\title{
Quantitative Analysis of the Superior Colliculus and the Parabigeminal Nucleus in the Hereditary Unilaterally Microphthalmic Rat*
}

\author{
By
}

\author{
Akira TOKUNAGA $^{1}$, Katsumi OTANI ${ }^{1}$ Shoei SUGITA ${ }^{1}$ \\ and Katsutoshi TERASAWA ${ }^{2}$
}

\author{
1: The Third Department of Anatomy, School of Medicine, Chiba University. \\ 1-8-1 Inohana, Chiba 280, Japan \\ 2: Department of Oriental Medicine, Toyama Medical and Pharmaceutical University. \\ 2630 Sugitani, Toyama 930-01, Japan
}

\begin{abstract}
Key Words: Unilateral Micropthalmia, Rat, Superior colliculus, Parabigeminal nucleus.
Summary: Quantitative morphological changes in the superior colliculus (SC) and the parabigeminal nucleus (PB) were studied in hereditary unilaterally microphthalmic rats. The mutant animals have one vestigial and one almost normally developed eyeball. The former eye completely lacks the optic nerve. The proportion of uncrossed to crossed retinal fibers in the mutant rats was estimated at about $6 \%$. Conspicuous changes in SC were found only on the contralateral side of the abnormal eye. Relative volume of the superficial layers of SC (SCS) to the central gray matter (SGC) was decreased to $50 \%$ of the normal. However, the cell density in SCS increased up to $130-190 \%$ of the normal. The str. griseum superficiale consisted mainly of small roundish neurons in dense and irregular arrangements. Small amounts of fibers were observed in the medial $1 / 3$ of the str. opticum, but very few in the lateral $2 / 3$. No significant changes were found in the deeper collicular layers of the mutant rats.

Unilaterally microphthalmic PB was subdivided normally into three parts: the dorsal (PBd), middle (PBm) and ventral subdivisions (PBv). The relative volumes of each PB subdivision on both sides had decreased to 57 to $65 \%$ of the normal, except for that of PBv on the contralateral side to the anomalous eye ( $26 \%$ of the normal). Cell densities of $\mathrm{PB}$ were slightly lowered (76-84\% of the normal) in PBm and PBv, but not much in PBd (88-90\% of the normal) on both sides.
\end{abstract}

Uncrossed retinal fibers of rats are reported to terminate in a restricted region of the superficial gray and optic layers of the superior colliculus. (SC) $)^{8,13,24,26)}$. It has been also well documented that prenatal or neonatal removal of one eye in experimental animals resulted in the marked expansion of the terminal field in the uncrossed retinal projection (see Discussion). The expanded distribution was observed not only in the superficial layers of SC (SCS) but also in the lateral geniculate nucleus of either the

Correspondence to: Prof. Katsumi Otani, The Third Department of Anatomy, School of Medicine, Chiba University. 1-8-1 Inohana, Chiba 280, Japan

*This paper is dedicated to Dr. Kazuyo Shimai, Emeritus Professor of Keio University Medical School, on his retirement. 
experimentally induced ${ }^{23)}$ or the congenital unilaterally micro- ${ }^{39)}$ and anophthalmic animals ${ }^{9}$ ).

Tokunaga et al. ('85) ${ }^{40)}$ quantitatively demonstrated a significant hypoplasia of SCS in the bilaterally microphthalmic rats. An autopsy report of the uniocular blindness revealed no morphological changes in the mesencephalic tectum ${ }^{14}$ ). On the other hand, remarkable reduction in the size of contralateral SC has been reported in experimental animals having one eye removal at $\operatorname{birth}^{6,7,9,15,27,29,37,41)}$. However, little is known about the quantitative morphological changes in the visual centers of hereditary unilaterally micro- or anophthalmic animals. The uni- and bilaterally microphthalmic rats, which are maintained with brother-sister matings in our laboratory, lack completely the optic nerve on one and both sides, respectively, due to growth inhibition of the optic cup at the early embryonic stage $\mathrm{e}^{20}$ ). It is of interest to find out what sort of influences could be exerted by the expanded uncrossed retinotectal fibers upon developing $\mathrm{SC}$ in the mutant rat.

Recently, the parabigeminal nucleus (PB) the secondary visual centers in the midbrain because of its intimate connections with $\mathrm{SC}^{2,12,42)}$. It can be expected that $\mathrm{PB}$ in the unilaterally microphthalmic rats is also involved in some structural changes during its development under the influence of the altered SC.

In this study morphological changes of SC and PB in the unilaterally microphthalmic rats will be described, with special rerefence to quantitative analysis, as well as a comparison, with those in bilateral microphthalmia ${ }^{40)}$.

\section{Materials and Methods}

Nine unilaterally microphthalmic rats (Donryu), ranging from 5 to 7 months old (body weight, 250-350 g), were used with 6 normal rats from the same strain as control. Animals were anesthetized with sodium amobarbital $(60 \mathrm{mg} / \mathrm{kg}$ body weight) and perfused transcardially with a brief rinse of physiological saline $(100 \mathrm{ml} / \mathrm{each}$ animal $)$ followed by $300 \mathrm{ml}$ of buffered $10 \%$ formaline ( $\mathrm{pH} 7.4)$. The brain was stored in the same fixative for 1 week at $4^{\circ} \mathrm{C}$, and then embedded in celloidin. Serial coronal sections were cut at $25 \mu \mathrm{m}$ and every other section was stained by the Klüver-Barrera method.

In order to compare the width of the optic tract, the relative thickness of the tract to the diameter of the anterior commissure was estimated as follows:

$$
\mathrm{B} / \mathrm{A} \times 100(\%)
$$

A. Diameter of the anterior commissure measured at its midline in a coronal section. B. Mean width of the optic tract measured on three successive coronal sections through $1 \mathrm{~mm}$ caudal to the posterior margin of the commissure (Fig. 1A).

Besides the unilateral microphthalmia, the optic tracts from 6 bilaterally microphthalmic rats ${ }^{40)}$ without optic nerve on both sides were also examined. Ratio of the volume of the superficial tectal layers (the zonal, superficial gray and optic strata: SCS), of the deeper collicular layers (from the intermediate gray to the deep white laminae: SCD), and of $\mathrm{PB}$ to the volume of the central gray matter (SGC) beneath SC were determined as follows: Contours of SCS, SCD and SGC, and of PB in each coronal section were drawn with a camera lucida at a magnification of 44, and 100x, respectively, and then each area was measured with a digitizer system (Model G-6C, MUTOH Co., Tokyo). The measurement reliability was tested by comparing five subsequent analyses of a given figure by the same person (S.S.). Differences did not exceed $7 \%$. Total volume of a given nucleus was estimated by multiplying the total area by the thickness of the section. Relative volume in percent was determined 

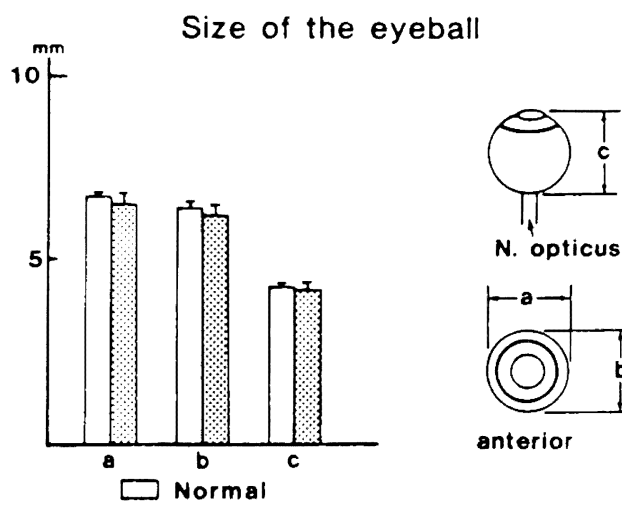

A

Unilat. Microphthalmia

(a and b, N:12. C, N:10)
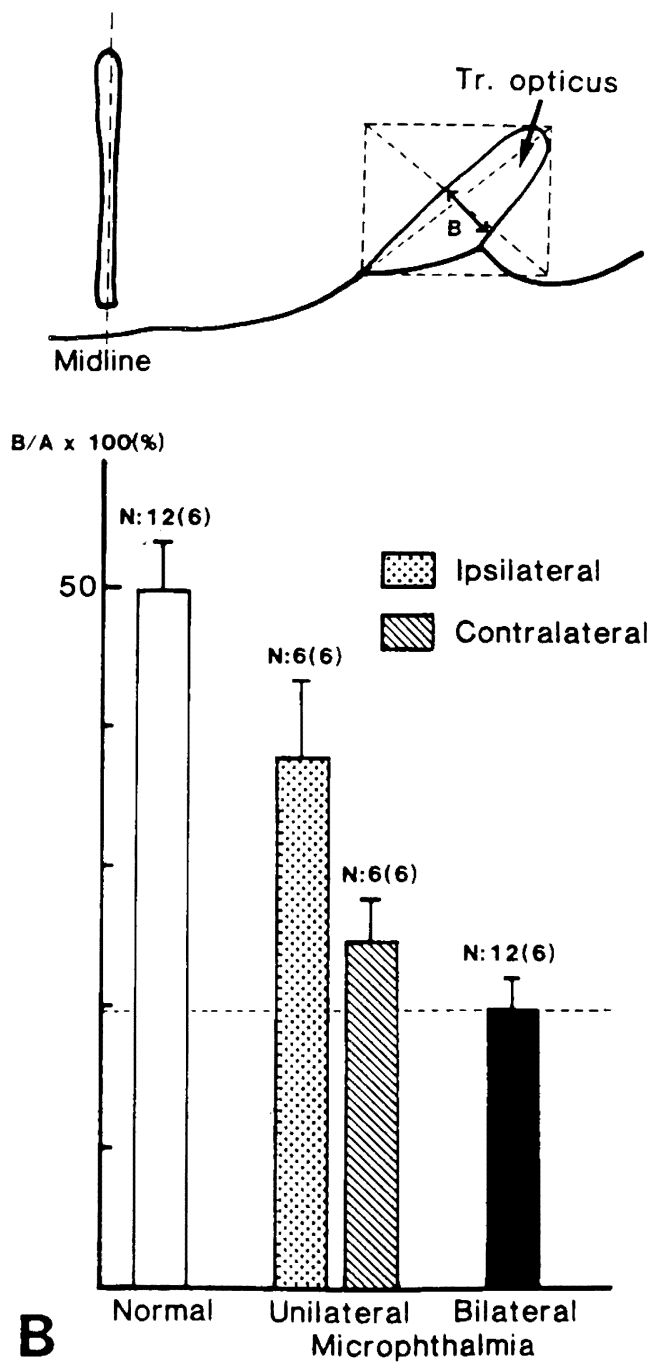

as follows (Fig. 3A):

$$
\frac{\text { Total volume of a given nucleus }}{\text { Total volume of SGC }} \times 100(\%)
$$

Number of neurons in a given nucleus was counted by means of an ocular grid $(25 \times 25 \mu \mathrm{m})$ which was superimposed on the microscopic image at randomly selected angles at a magnification of $600 x$. Then the cell density per unit area (cells $/ 50^{2} \mu \mathrm{m}^{2}$ ) was determined.

Cell size was represented by the long and short axes of randomly selected neurons in a plane containing the cell nucleus. Statistical differences between the groups were examined by the Student's t-test.

\section{Results}

The unilaterally microphthalmic rats have one vestigial and one almost normally developed eyeball. The former eye completely lacks the optic nerve (Fig. 8A and B). The size of the latter eyeball was not significantly different from that of the normal (Fig. 1A). The bilaterally microphthalmic rat showed a thin but very apparent optic tract on both sides (about $40 \%$ of the width of the normal tract) (Figs.1B and 8D). These non-retinal fibers of the optic tract form the commissure of Gudden. In the unilateral microphthalmia, the respective proportions between the optic tract contralateral (Fig. $8 \mathrm{~F}$ ) and ipsilateral (Fig. 8E) to the vestigial

Fig. 1. A: Size of the normally developed eyeball in unilaterally microphthalmic rats is not significantly different from that of the normal eyeball.

B: Relative thickness of the optic tract to the diameter of the anterior commissure; B/A $\times 100(\%)$. A: Diameter of the anterior commissure at its midline in a coronal section. B: Mean width of the optic tract measured on three successive coronal sections through $1 \mathrm{~mm}$ caudal to the posterior margin of the commissure. 
eye were 49 and $76 \%$ of the width of the normal tract (Fig. 1B). This means that 9 and $36 \%$ of the width of the optic tract were occupied by the uncrossed and the crossed retinal fibers, respectively.

Superior colliculus:

In the unilaterally microphthalmic rats,

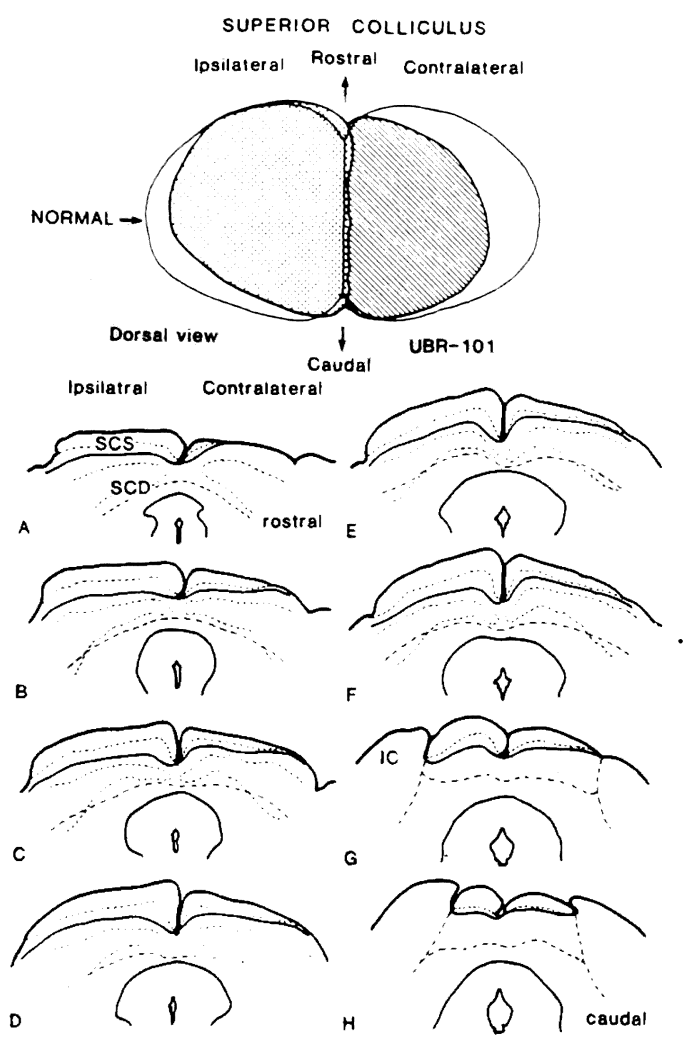

Fig. 2. Diagrammatic representation of the superior colliculus of a unilaterally microphthalmic rat (UBR-101). The superficial layers of the colliculus (SCS) contralateral to the vestigial eye are much thinner than those of ipsilateral SCS, receiving crossed retinal fibers from the normally developed eye. No changes are found in the deeper collicular layers (SCD) on both sides. Dorsal view of the superior colliculus, reconstructed using serial coronal sections, exhibits noticeable reduction of size on its contralateral side, in which uncrossed optic fibers are distributed. Sections $A$ and $\mathrm{H}$ are the most rostral and the most caudal, respecitively. IC: inferior colliculus. conspicuous changes in the superficial layers of the superior colliculus (SCS) were found on the contralateral side to the vestigial eye, receiving uncrossed retinal fibers, but not on the ipsilateral SCS in which crossed retinal fibers terminate. Contralateral SCS showed a marked reduction in its size (Figs. 2 and 9B), and the midline between the two SCSs is displaced towards the contralateral side of the abnormal eye (Fig.2). Small amounts of fibers were found in the medial $1 / 3$ of the str. opticum (SO), with very few in the lateral $2 / 3$.

The boundary between SCS and SCD (i.e., between $\mathrm{SO}$ and the intermediate gray layer) in the shrunken $\mathrm{SC}$ was determined by some medium-sized polygonal cells scattered in the ventral part of SO (Fig. 9B). The relative volume of SCS to SGC was decreased to about $50 \%$ of the normal on the contralateral side to the vestigial eye $(p<0.01)$, but not on the ipsilateral side ( $85 \%$ of the normal) (Fig.3B). Cell density of contralateral SCS was markedly increased (133, 151 and $189 \%$ in the zonal, superficial gray and optic layers, respectively; $\mathrm{p}<0.01)$, but not in the ipsilateral SCS $(100,102$ and $108 \%$ in the respective three layers) (Fig.4A). SCD showed no significant changes in not only the relative volume but also the cell density between the unilaterally microphthalmic and normal rats (Figs. 3B and 4B). The str. griseum superficiale (SGS) of the normal rat consisted mainly of small neurons (long and short axes: $8-12$ and 5-8 $\mu \mathrm{m}$ respectively) with fusiform to oval cell bodies, orienting their long axis perpendicularly to the collicular surface (Figs. 5 and 10A). In the mutant rat, contralateral SCS was packed with small and roundish neurons (diameter of 5-8 $\mu \mathrm{m}$ ) (Figs. 5, 9B and 10B). Although the size of the cell nucleus was almost identical to the normal, the SCS neurons were found to reduce their perikaryal size. In addition, the narrow perikaryal fringe, having a small amount of Nissl 
SUPERIOR COLLICULUS

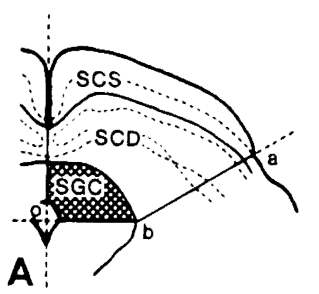

A
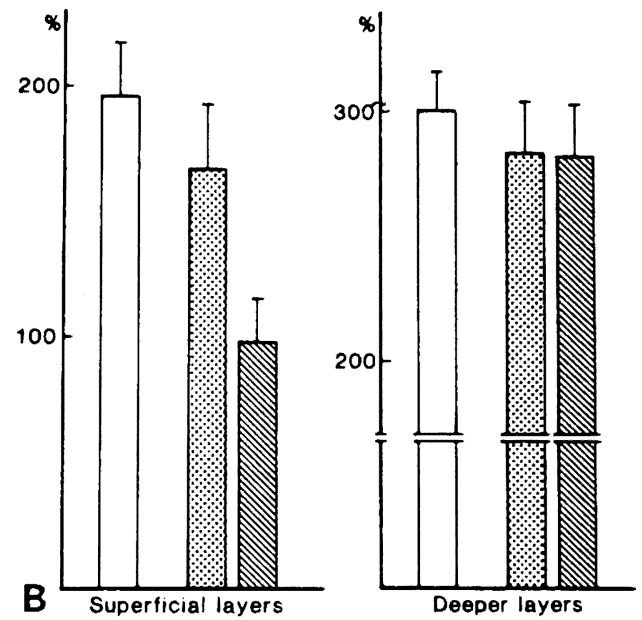

Fig. 3. A: Boundaries of the superior collicular layers and the central gray substance. Line bo: Horizontal line through the center of the aqueductal lumen. Line $a b$ : Boundary between the tectum medially and the tegmentum laterally. SCS: Superficial collicular layers, from surface of the tectum to the ventral margin of the optic layer. SCD: Deeper collicular laminae, from the ventral margin of the str. opticum to the ventral margin of the str. opticum to the ventral margin of the str. album profundum. SGC: Meshed area of the substantia grisea centralis beneath the superior colliculus. Relative volume of SCS to SGC: Total volume of SCS/ total volume of SGC $x$ $100(\%)$. Relative volume of SCD: Total volume of SCD/total volume of SGC $x$ $100(\%)$. Number in parenthesis indicates number of animals examined.

B: Histogram of the relative volumes of SCS, and of SCD, to SGC. The relative volume of unilaterally microphthalmic SCS contralateral to the vestigial eye decreased to $50 \%$ of the normal, while no significant differences were observed in ipsilateral SCS. There are no significant differences in SCD between the normal and the mutant rats. substance, was pale in appearance and the nucleolus was slightly indistinct as compared to the normal. No nerve cells with two nucleoli were observed in the microphthalmic SCS. SO of the normal tectum contained considerable numbers of medium. sized (long axis, 10-12 $\mu \mathrm{m}$; short axis, $8-15 \mu \mathrm{m})$ polygonal neurons. Although the number of SO neurons was apparently diminished in the contralateral SCS, they were distributed in the ventral part of SO, demarcating ventrally the str. griseum intermedium, as mentioned above. The cell size of ipsilateral SCS showed no marked changes as compared with that of the normal

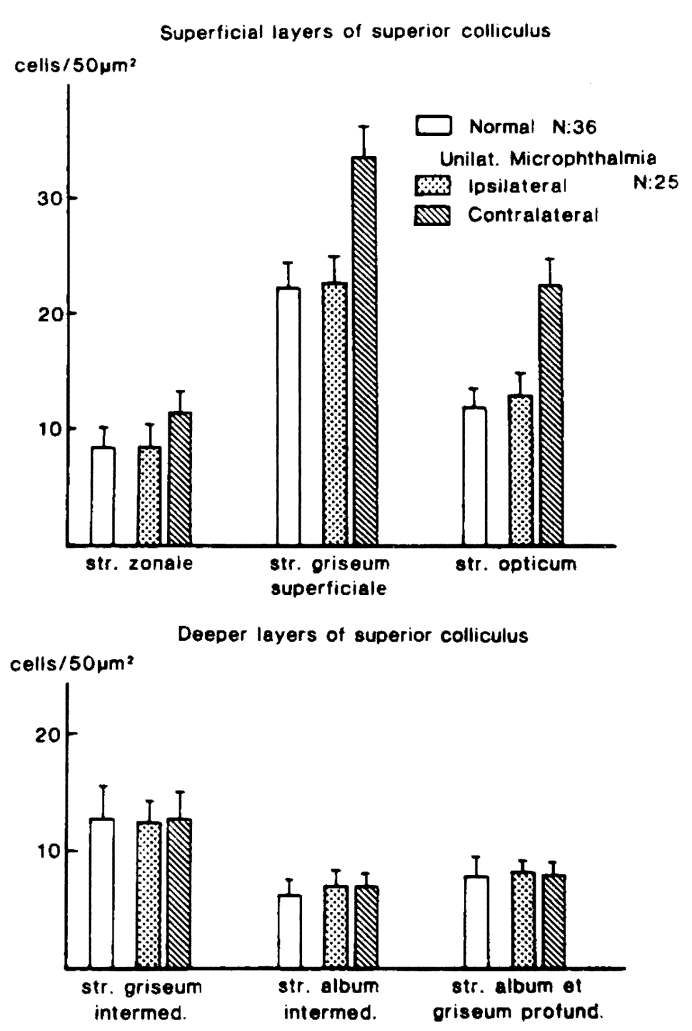

Fig. 4. Cellular density per unit area in each collicular layer. Note that three superficial laminae of unilaterally microphthalmic SC on the contralateral side show very high neuronal densities $(130-190 \%$ of the normal), while there are no significant differences on the ipsilateral side to the abnormal eye. No noticeable changes are present in the deeper collicular layers. 

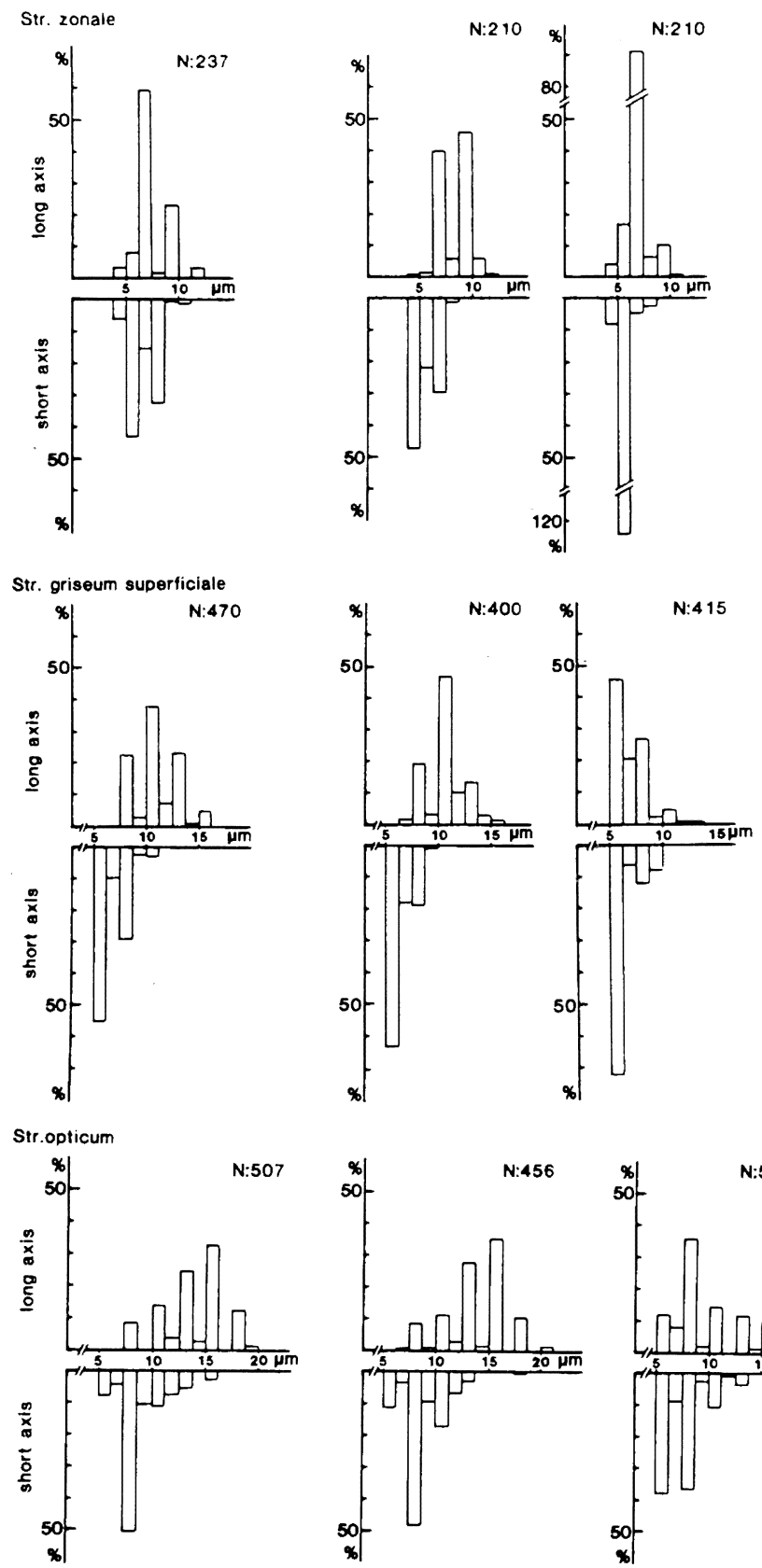

NORMAL

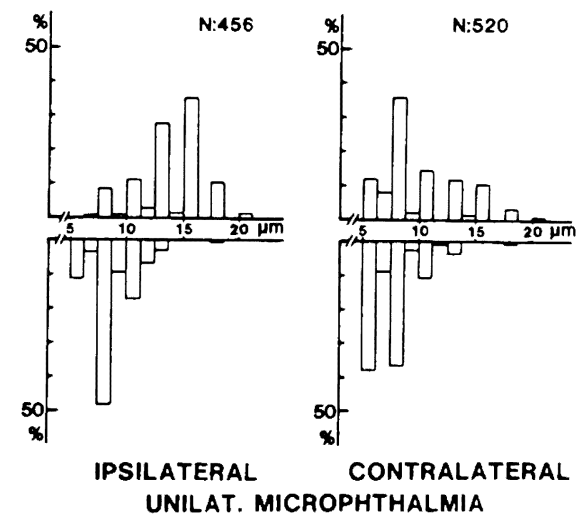

Fig. 5. Cell size distribution of SCS neurons in normal and unilaterally microphthalmic rats. Most of the SCS neurons on the contralateral side in the mutant animals have shorter long axes as cocompared with those in normal SCS, so as to present a roundish appearance. However, no marked changes are found in ipsilateral SCS. 
(Fig. 5). There were no significant differennces in the cell size of SCD neurons between the microphthalmia and the normal.

\section{Parabigeminal nucleus:}

The normal parabigeminal nucleus (PB) is subdivided into three subgroups: the dorsal $(\mathrm{PBd})$, middle $(\mathrm{Bm})$ and ventral parts
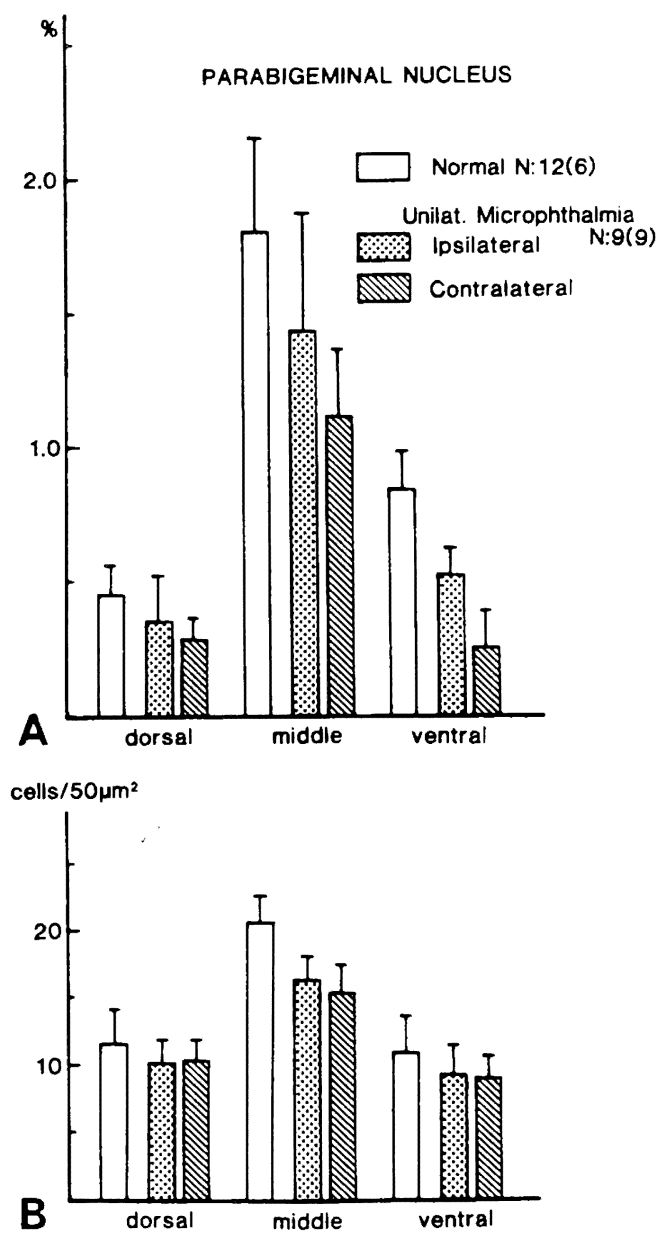

Fig. 6. Histograms of the relative volume of the parabigeminal nucleus ( $\mathrm{PB}$ ) to the central gray matter $(\mathrm{A})$, and of the cellular density per unit area in PB (B). The relative volumes of each subdivision are severely decreased in the contralateral compared to the ipsilateral sides of the unilateral microphthalmia. The neuronal population of $\mathrm{PB}$ in the mutant rat is slightly lowered in $\mathrm{PBm}$ and $\mathrm{PBv}$, but not in PBd, on both sides. Number in parenthesis indicates number of animals examined.
$(\mathrm{PBv})^{38)}$ (Fig. 10A). In spite of its reduced size in the unilaterally microphthalmic rats, $\mathrm{PB}$ is still normally subdivisible into the three subgroups (Fig. 10B). Relative volumes of each $\mathrm{PB}$ subgroup on both sides to SGC were significantly decreased in the mutant animals $(\mathrm{PBm}$ and $\mathrm{PBv}, \mathrm{p}<0.01$, $\mathrm{PBd}, \mathrm{p}<0.05$ ) as compared to the normal (Fig. 6A). The relative volume of $\mathrm{PBv}$ to SGC was markedly decreased in the contralateral in comparison to the ipsilateral side to the vestigial eye ( 26 and $61 \%$ of the normal, respectively, $\mathrm{p}<0.01$ ). However, the relative volumes of $\mathrm{PBd}$ and $\mathrm{PBm}$ to $\mathrm{SGC}$ showed no significant differences between the ipsilateral (65 and $60 \%$ of the normal, respectively) and the contralateral sides (58 and $57 \%$ of the normal, respectively). Cell density was slightly lowered in the PBm on both sides as compared with the normal (ipsi- and contralateral sides; 86 and $84 \%$ of the normal, respectively, $\mathrm{p}<0.01$ ), but not in the PBd (ipsi- and contralateral sides; 88 and $90 \%$ of the normal) (Fig. 6B).

In normal rats, $\mathrm{PBm}$ was mainly composed of neurons with round to polygonal cell body with a long axis of 10 to $17 \mu \mathrm{m}$ (Figs. 7 and 10C). On the other hand, neurons in $\mathrm{PBd}$ and $\mathrm{PBv}$ were primarily fusiform in shape (long and short axes: 1015 and $7-12 \mu \mathrm{m}$, respectively)(Figs. 7 and 10D). In the unilaterally microphthalmic rats, the size of neurons in the three PB subgroups on both sides was definitely reduced and their cell body showed a fusiform to oval shape (long and short axes: $7-15$ and $5-10 \mu \mathrm{m}$, respectively) (Fig. 7). Perikarya of the PB neurons contained a small amount of Nissl granules and had a pale appearance. The size of the cell nucleus was found to be nearly the same as that of the normal.

In all the mutant animals examined in this study, no other malformations were observed except for changes in relay nuclei in the central visual system associated with altered retinal axonal ingrowth. 

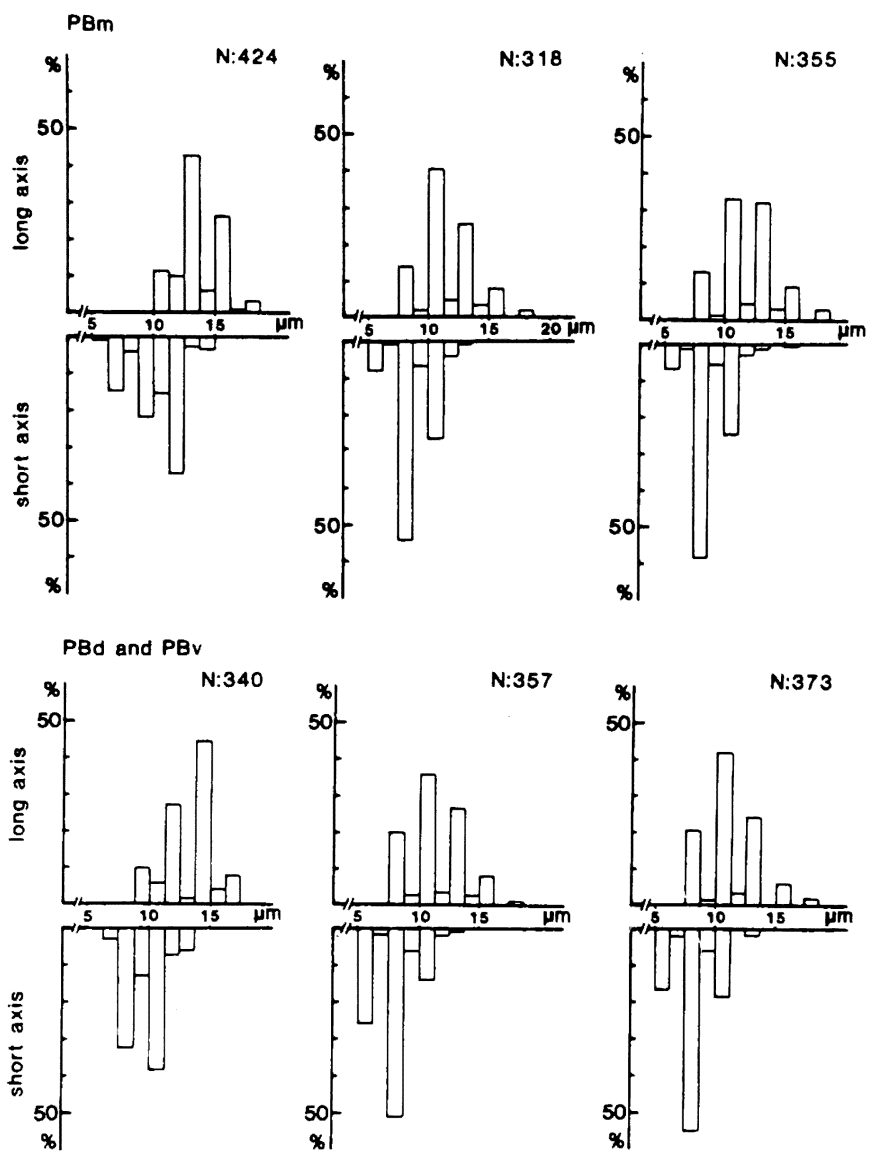

NORMAL

IPSILATERAL CONTRALATERAL UNILAT. MICROPHTHALMIA

Fig. 7. Cell size distribution of the parabigeminal neurons. Most of the neurons in the mutant rats are smaller than those in the normal.

\section{Discussion}

A study of the organogenesis of the microphthalmic eye revealed that growth inhibition of the inner layer of the optic cup at the 13th embryonic day resulted in complete loss of the optic nerve ${ }^{20}$ ) The present observation disclosed that in the unilaterally microphthalmic rats uncrossed and crossed retinal fibers from the normally developed eye occupied 9 and $36 \%$ of the width of the optic tract, respectively. The ratio of uncrossed to crossed optic fibers is, therefore, estimated at 1 to 16 . So it is assumed that in the mutant animals about $6 \%$ of retinal fibers entered into the ipsilateral optic tract as an uncrossed retinofugal projection. The proportion of uncrossed to crossed retinal fibers falls into the range of values that can be seen in rodents $(5-10 \%)^{13,24,31)}$.

The present morphological observation exhibited that the volume of SCS contralateral to the vestigial eye decreased to $50 \%$ of the normal, while its cell density increased up to $130-190 \%$. On the other hand, ipsilateral SCS, receiving crossed optic fibers, and SCD on both sides of the mutant rats remained unchanged. It is well documented that the removal of one eye in newborn animals results in a marked reduction in the 
volume of contralateral $\operatorname{SCS}^{6,7,9,15,27,29,37}$, 41). Tsang $\left({ }^{\prime} 37\right)^{41)}$ and Lund et al. $(' 73)^{27)}$ reported respectively that in adult rats (4-19 months old) SC contralateral to the eye removed at birth shrunk by 45 and $55 \%$ of that of the unoperated rats. On the other hand, DeLong and Sidman $\left({ }^{\prime} 62\right)^{7)}$ observed a mild diminution of the collicular size (73$78 \%$ of the control SC) in 1.7 months-old mice, whose eyes had been unilaterally enucleated at birth. Tsang $\left({ }^{\prime} 37\right)^{41)}$ pointed out that the atrophy was proportional to the period after deaffrentation. It is, therefore, reasonable to consider that the survival period of 4-19 months (materials of Tsang ${ }^{44)}$, Lund et al. ${ }^{27)}$ and the present study) induced a greater reduction of SC volume than that of 1.7 months (DeLong and Sidman $)^{7)}$. Although Godement et al. $\left.\left({ }^{\prime} 80\right)^{9}\right)$ have described a marked reduction of size in both the lateral geniculate nucleus and SC of the unilaterally anophthalmic mice, quantitative morphological changes in the hereditary unilateral microphthalmia are hereby presented for the first time.

Many reports have been issued on the remarkable expansion of the terminal field in the uncrossed retinal projection following prenatal or neonatal removal of one eye $5,9,10,17-19,21,22,27,28)$. Godement et al. $\left({ }^{\prime} 80\right)^{9)}$ and Tokunaga et al. $\left({ }^{\prime} 85\right)^{39)}$ observed enlarged distribution of the uncrossed retinal pathway in the hereditary unilaterally ano- and microphthalmic animals, respectively. Rats with unilateral eye defects induced by tripan-blue administration ${ }^{23)}$ also showed the expansion of the ipsilateral optic projection throughout the dorsal lateral geniculate nucleus (CGLd) and SCS. The relative volume of SCS to SGC in the bilaterally microphthalmic rats decreased to $35 \%$ of the normal ${ }^{40)}$. Therefore, it is reasonable to conclude that the expanded ipsilateral retinal projection caused a slight increase in the volume of SCS in the uni- lateral microphthalmia (about 15\% of the normal). Cell size and morphological changes in neurons of SCS contralateral to the vestigial eye were similar to those found in the bilateral microphthalmia ${ }^{40}$ ). Sugita et al. $\left({ }^{\prime} 83\right)^{35)}$ demonstrated in their WGA-HRP study that neurons in str. griseum superficiale (SGC) projected their fibers to CGLd and those in the str. opticum (SO) to the lateroposterior thalamic neucleus (LP). This segregation of the tecto-thalamic projections was apparently preserved in the bilaterally microphthalmic rats $^{36}$ ). However, the amounts of the CGLdand the LP-projection neurons decreased to 3 and $50 \%$ of the normal, respectively, in the mutant animals ${ }^{36}$ ). As cell density was not so greatly changed between the unilateral and the bilateral microphthalmia ${ }^{40)}$, the slight increase of volume of SCS (15\% of the normal) contralateral to the anomalous eye in the present materials suggests that the cell population itself had definitely increased in the shrunken SCS. Therefore, it is possible to assume that most of the SCS neurons are shared in forming the efferent projections to the thalamic nuclei.

Goodman et al. $(73)^{8)}$ pointed out two routes of the ipsilateral tectal afferents: a rostral and a lateral route. The rostral route passes caudally through the nucleus of the optic tract and enters the rostral aspect of SC to distribute in its medial half. The lateral route, on the other hand, runs in the brachium of SC and enters the lateral aspect of SC to distribute in its lateral half. Unilateral microphthalmic SCS contralateral to the vestigial eye showed definite fiber bundles in the medial $1 / 3$ of SO, but very few in the lateral $2 / 3$. This finding suggests that in the unilaterally microphthalmic rats the expanded uncrossed retinotectal fibers arrive at SC mainly via the rostral route.

It is well established in many experimental animals that $\mathrm{PB}$ is reciprocally and 
almost restrictively connected with $\mathrm{SC}^{11,12}$, $16,25,34,42)$. The present study revealed that $\mathrm{PB}$ in the unilaterally microphthalmic rats was subdivided normally into the 3 subgroups. The relative volumes of each subgroup on both sides to SGC decreased to $57-65 \%$ of the normal, except for that of $\mathrm{PBv}$ on the contralateral side to the abnormal eye $(26 \%)$. On the other hand, no subdivisions were observed in the bilaterally microphthalmic $\mathrm{PB}^{40}$ ). The reduction of the relative volume and of the cell density were much more severe in the bilateral (30 and $75 \%$, respectively) ${ }^{40)}$ than in the unilateral microphthalmia.

Altman and Bayer $\left({ }^{\prime} 81\right)^{1)}$ studied the cytogenesis of the rat brain stem structures with the ${ }^{3} \mathrm{H}$-thymidine autoradiographic method. Neurons of PB were produced between 13- and 15-day embryonic stages with a peak on the 14 th day ${ }^{1}$. The generation of SCS neurons begins on the 11 th or 12 th embryonic day and ends by the 18 th embryonic day ${ }^{1,3}, 7,39$ ). The crossed and uncrossed retinal fibers of the rat are reported to reach SCS by the 16 th and 17 th embryonic day, respectively ${ }^{4}$. Furthermore, Stevenson and Lund ('82) ${ }^{34}$ ) demonstrated a corresponding intra-SCS distribution pattern of projection fibers from contralateral $\mathrm{PBm}$ and from the ipsilateral retina of rats with unilateral eye removal at birth. These findings indicate not only developmental but also some functional independence between SCS and PB. Therefore, the mild changes in the unilateral microphthalmic PB can be attributed to the existence of expanded distribution of the uncrossed retinotectal fibers in SCS.

The present finding showing severe reduction in the volume of $\mathrm{PBv}$ on the same side as the collapsed SCS is difficult to explain. Tokunaga et al. $\left({ }^{\prime} 85\right)^{40)}$ pointed out that the uncrossed retinal fibers in the unilaterally microphthalmic rats were densely distributed to the entire depth of the medial $2 / 3$ of SCS, while scarcely to the lateral $1 / 3$. Their result may suggest a fiber connection between $\mathrm{PBv}$ and the lateral $1 / 3$ of SCS. On the other hand, a topographical study on the tecto-PB projection in rats ${ }^{25)}$ seems to eliminate such a possibility. Further research needs to be done on the connectivity of the parabigeminal nucleus.

\section{Acknowledgements}

The authors wish to thank Mr. K. Miyama, Mrs. F. Saito and Mrs. T. Saito for their expert technical assistance. We are also very grateful to Dr. A. Gerz for his critical review of the manuscript. This work was supported by a grant in aid for Fundamental Scientific Research from the Japanese Ministry of Education, Science and Culture (No. 60570023).

\section{References}

1) Altman, J. and Bayer, S.A, Time of origin of neurons of the rat superior colliculus in relation to other components of the visual and visuomotor pathways. Exp. Brain Res. 42: 424-434, 1981.

2) Baleydier, C. and Magnin, M., Afferent and efferent connections of the parabigeminal nucleus in cat revealed by retrograde axonal transport of horseradish peroxidase. Brain Research, 161 . 187-198, 1979.

3) Brückner, G., Mares, V. and Biesold, D., Neurogenesis in the visual system of the rat. An autoradiographic investigation. J. Comp. Neuropl., 166: 245-256, 1976.

4) Bunt, S.M., Lund. R.D. and Land, P.W., Prenatal development of the optic projection in albino and hooded rats. Develop. Brain Res., 6: 149-168, 1983.

5) Chow, K.L., Mathers, L.H. and Spear, P.D., Spreading of uncrossed retinal projection in superior colliculus of neonatally enucleated rabbits. J.Comp. Neurol., 151: 307-322, 1973.

6) Chow, K.L., Ostrach, L.H., Crabtree, J.W., Bernegger, O., Baumbach, H.D. and Lawson, R., Anomalous uncrossed retinal projections fail to activate superior colliculus neurons in rabbits unilaterally enucleated by fetal surgery. J. Comp. Neurol., 196: 189-204, 1981.

7) DeLong, G.R. and Sidman, R.L., Effects of eye removal at birth on histogenesis of the 
mouse superior colliculus: An autoradiographic analysis with tritiated thymidine. J. Comp. Neurol., 118: 205-223, 1962.

8) Goodman, D.C., Bogdasarian, R.S. and Horel, J.A., Axonal sprouting of ipsilateral optic tract following opposite eye removal. Brain Behav. Evol., 8: 27-50,1973.

9) Godemen, P., Saillour, P. and Imbert, M., The ipsilateral optic pathway to the dorsal lateral geniculate nucleus and superior colliculus in mice with prenatal or postnatal loss of one eye. J. Comp. Neurol., 190: 611-626, 1980.

10) Godement, P., Salaün, J. and Imbert, M., Prenatal and postnatal development of retinogeniculate and retinocollicular projections in the mouse. J. Comp. Neurol., 230: 552-575, 1984.

11) Graham, J., An autoradiographic study of the efferent connections of the superior colliculus in the cat. J. Comp. Neurol., 173: 629-654, 1977.

12) Graybiel, A.M., A satellite system of the superior colliculus: The parabigeminal nucleus and its projections to the superficial collicular layers. Brain Research, 145: 365-374, 1978.

13) Hayhow, W.R., Sefton, A and Webb, C., Primary optic centers of the rat in relation to the terminal distribution of the crossed and uncrossed optic nerve fibers. J. Com. Neurol., 118: 295-321, 1962.

14) Hechst, B., Über das Verhalten der äußeren Kniehöcker und der Sehrinde bei einseitiger peripherer Blindheit. Arch. Psychiat., 100: 19-31, 1933.

15) Hess, A., Optic centers and pathways after eye removal in fetal guinea pigs. J. Comp. Neurol., 109: 91-115, 1958.

16) Jen, L.S., Dai, Z.-G. and So, K.-F., The connections between the parabigeminal nucleus and the superior colliculus in the golden hamster. Neurosci. Letters, 51: 189-194, 1984.

17) Jen, L.S. and Lund, R.D., Experimentally induced enlargement of the uncrossed retinotectal pathway in rats. Brain Research, 211: 37-57, 1981 .

18) Jen, L.S., So, K.-F. and Chang, A-B., An anterograde HRP study of the retinotectal pathways in albino and pigmented guinea pigs. Brain Research, 263: 331-335, 1983.

19) Jen, L.S., So, K.-F. and Woo, H.H., An anterograde HRP study of the retinocollicular pathways in normal hamsters and hamsters with one eye enucleated at birth. Brain Research, 294: 169-173, 1984.
20) Kobayashi, K. and Otani, K., Morphogenesis of the hereditary microphthalmia in a new strain of rat. J. Morphol., 167. 265-276, 1981.

21) Laemle, L.K. and Labriola, A.R., Retinocollicular projections in the neonatal rat: An anatomical basis for plasticity. Develop. Brain Res., 3: 317-322, 1982.

22) Land, P.W. and Lund, R.D., Development of the rat's uncrossed retinotectal pathway and its relation to plasticity studies. Science, 205 : 689-700, 1979.

23) Land, P.W., Polley, E.H. and Kernis, M.M., Patterns of retinal projections to the lateral geniculate nucleus and superior colliculus of rats with induced unilateral congenital eye defects. Brain Research, 103: 394-399, 1976.

24) LeVere, T.E., The primary visual system of rat: A primer of its anatomy. Physiol Physiol., 6: 147-169, 1978.

25) Linden, R. and Perry, V.H., Retrograde and anterograde-transneuronal degeneration in the parabigeminal nucleus following tectal lesions in developing rats. J.Comp. Neurol., 218 : 270-281, 1983.

26) Lund, R.D., Uncrossed visual pathways of hooded and albino rats. Science, 149: 1506$1507,1965$.

27) Lund, R.D., Cunningham, T.J. and Lund, J.S., Modified optic projections after unilateral eye removal in young rats. Brain, Behav. Evol., 8: 51-72, 1973.

28) Manford, M., Campbell, G. and Lieberman, A. R, Postnatal development of ipsilateral retino-geniculate projections in normal albino rats and the effects of removal of one eye at birth. Anat. Embryol., 170. 71-78, 1984.

29) Mathers, L.H.Jr., Effects of neonatal deafferentation on the superficial laminae of the superior colliculus. Brain Research, 126: 19-30, 1977.

30) Mustari, M.J., Lund, R.D. and Graubard, K.; Histogenesis of the superior colliculus of the albino rat: A tritiated thymidine study. Brain Research, 164 : 39-52, 1979.

31) Polyak, S., Optic nerves, chiasm, tracts and subcortical visual centers (Cahpter VI). The vertebrate visual system. pp. 315-318, The University of Chicago Press, Chicago and London, 1957.

32) Sefton, AJ. and Martin, P.R., Relation of the parabigeminal nucleus to the superior colliculus and dorsal lateral geniculate nucleus in the hooded rat. Exp. Brain Res., 56: 144-148, 1984. 
33) Stevenson, J.A. and Lund, R.D., A crossed parabigemino-lateral geniculate projection in rats blinded at birth. Exp. Brain Res., 45: 95-100, 1982.

34 ) Ibid., Alterations of the crossed parabigeminotectal projection induced by neonatal eye removal in rats. J. Comp. Neurol., 207: 191$202,1982$.

35) Sugita, S., Otani, K., Tokunaga, A. and Terasawa, K., Laminar origin of the tectothalamic projections in the albino rat. Neurosci, Letters, 43: 143-147, 1983.

36) Sugita, S., Otani, K., Tokunaga, A. and Terasawa, K., Distribution of the tectothalamic projection neurons in the hereditary microphthalmic rat. Exp. Brain Res., 60: 564$575,1985$.

37) Terry, R.J., Roland, A. and Race, J.Jr., Effects of eye enucleation and eyelid closure upon the brain and associated visual structures in the mouse. I. A. report on degenerative changes, J. Exp. Zool., 150: 165-183, 1962.

38) Tokunaga, A and Otani, K., Neuronal organization of the corpus parabigeminum in the rat. Exp. Neurol., 58: 361-375, 1978.

39) Tokunaga, A, Sugita, S. and Otani, K., The distribution of uncrossed retinal fibers in the unilaterally microphthalmic rat. Neurosci. Res., Suppl. 1, S 158, 1985.

40) Tokunaga, A, Sugita, S., Otani, K. and Terasawa, K., Quantitative morphological changes in the superior colliculus and the parabigeminal nucleus in the bilaterally microphthalmic rat. Develop. Brain Res., 23: 131$140,1985$.

41) Tsang, Y.C., Visual centers in blinded rats. J. Comp. Neurol., 66: 211-261, 1937.

42) Watanabe, K. and Kawana, E., Efferent projections of the parabigeminal nucleus in rats: A horseradish peroxidase (HRP) study. Brain Research, 168: 1-11, 1979. 


\section{PLATES}




\section{Explanation of Figures}

\section{Pla te I}

Fig. 8. Ventral view of a normal (A), and a unilaterally microph thalmic rat brain (B). Arrow in B indicates the optic nerve from a normally developed eye.

C-D: The optic tract of a normal (C), a bilateral (D) and a unilateral microphthalmia (E and F). Very thin optic tract (arrows in D) is definitely present in the bilaterally microphthalmic rat, in spite of its complete loss of the optic nerve. E: Ipsilateral side to the vestigial eye. The tract contains crossed retinal fibers from a normally developed eye. F: Contralateral optic tract to the anomalous eyeball contains uncrossed retinal fibers. *: nucleus supraopticus. Klüver-Barrera staining. Bar indicates $500 \mu \mathrm{m}$. 

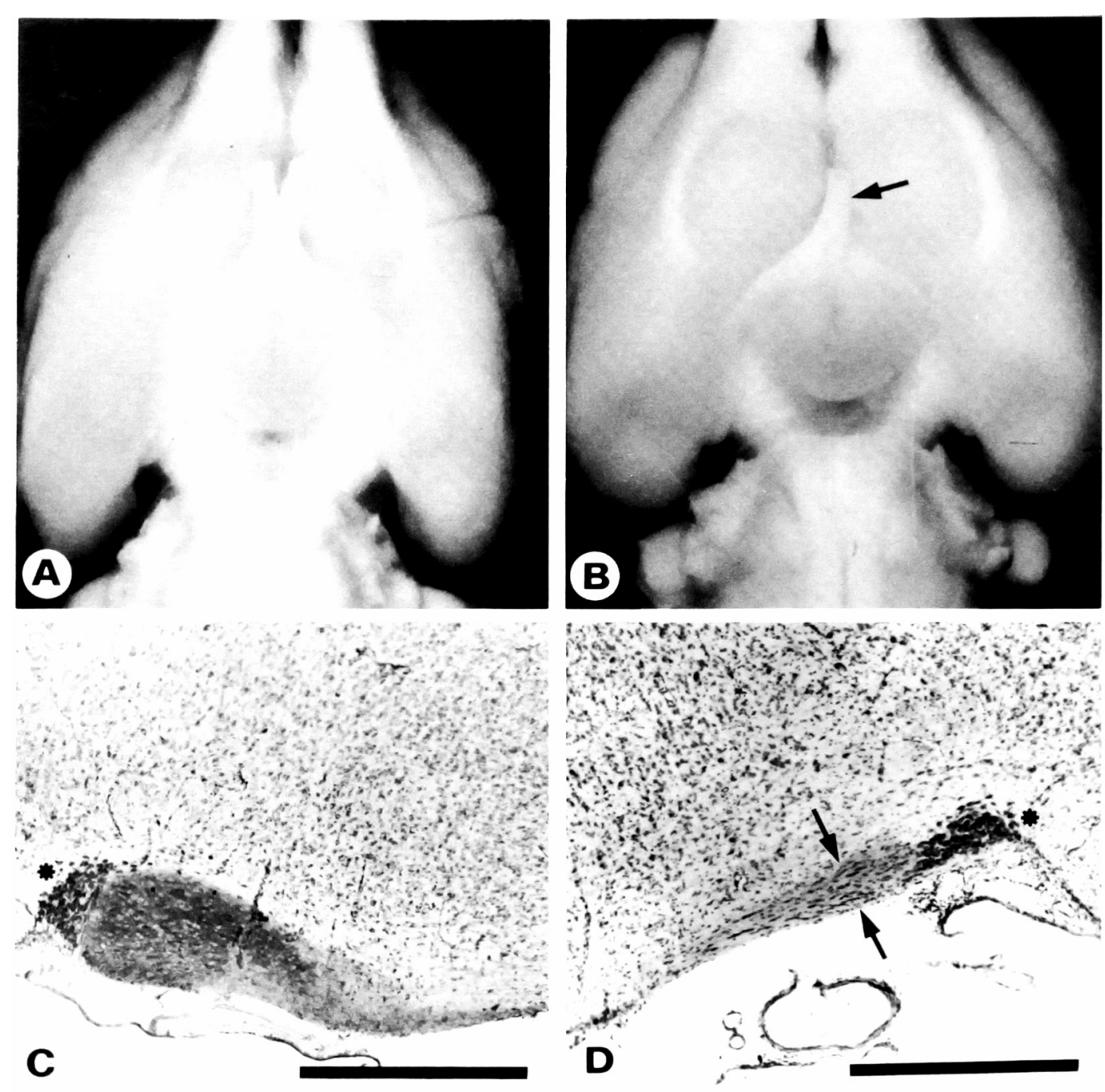

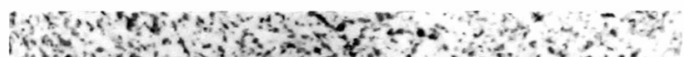

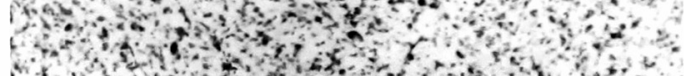

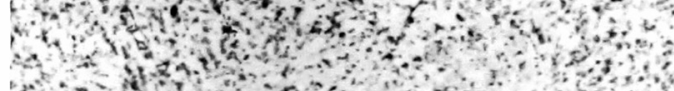

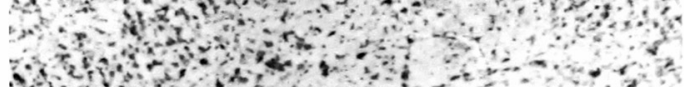
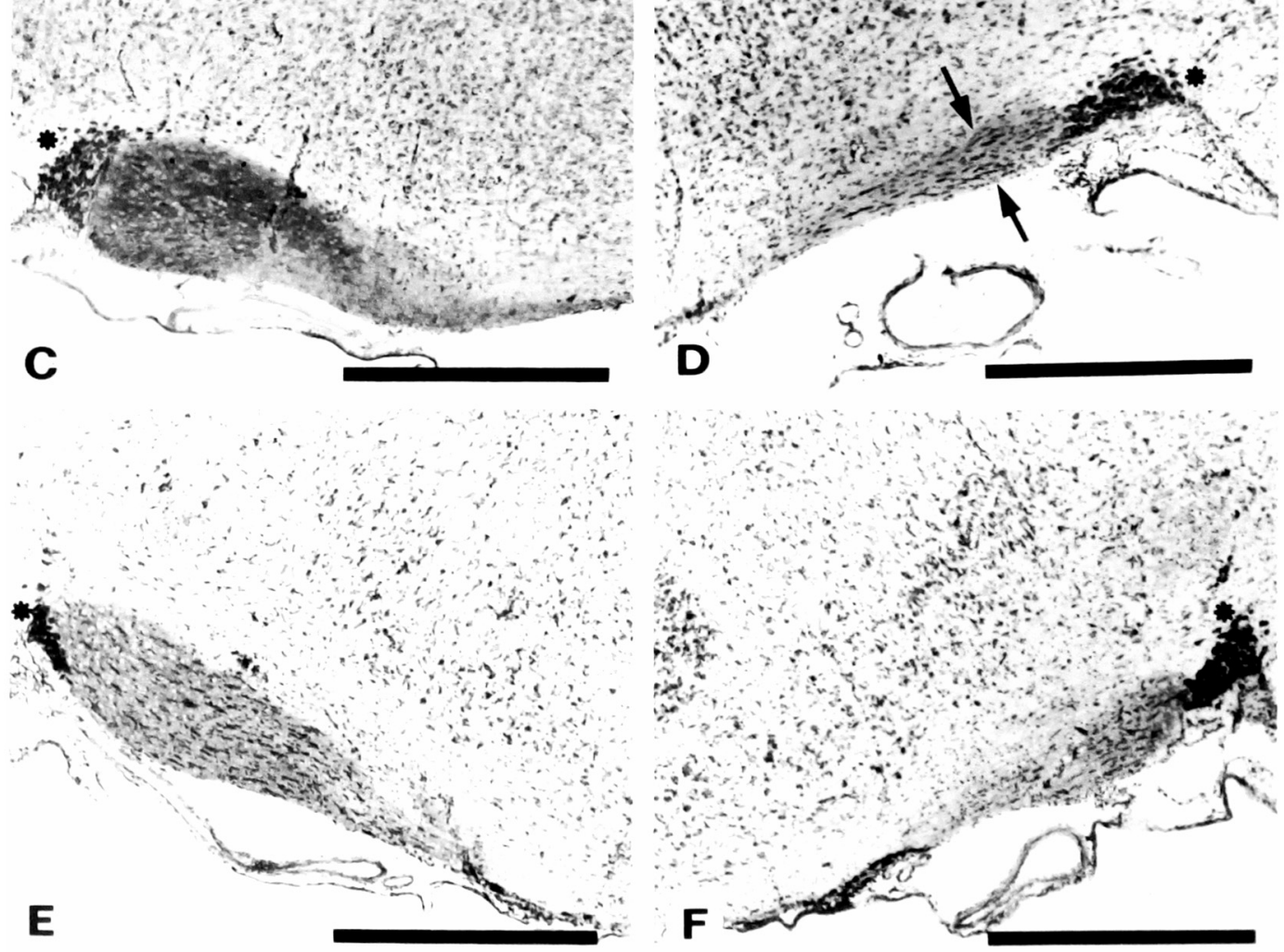


\section{Plate II}

Fig. 9. Cy toarchitecture of the unilaterally microphthalmic superior colliculus (SC) on the ipsilateral (A) and contralateral (B) sides to the vestigial eye. No remarkable changes were found between the ipsilateral side of mutant rats and the normal. On the other hand, the superficial layers (I to III) of the contralateral SC in unilateral microphthalmia are definitely collapsed and packed densely with small roundish neurons. The deeper tactal layers (IV to VII) of the mutant rats show no marked changes on both sides. Klüver-Barreta staining. Bar indicates $500 \mu \mathrm{m}$.

lateral microphthalmia are definitely collapsed and packed densely with small roundish neurons. The deeper tectal layers (IV to VII) of the mutant rats show no marked changes on both sides. KlüverBarrera staining. Bar indicates $500 \mu \mathrm{m}$.

I: str. zonale, II: str. griseum superficiale, III: str. opticum, IV: str. griseum intermedium, V: str. album intermedium, VI: str. griseum profundum, VII: str. album profundum, SGC: substantia grisea centralis. 


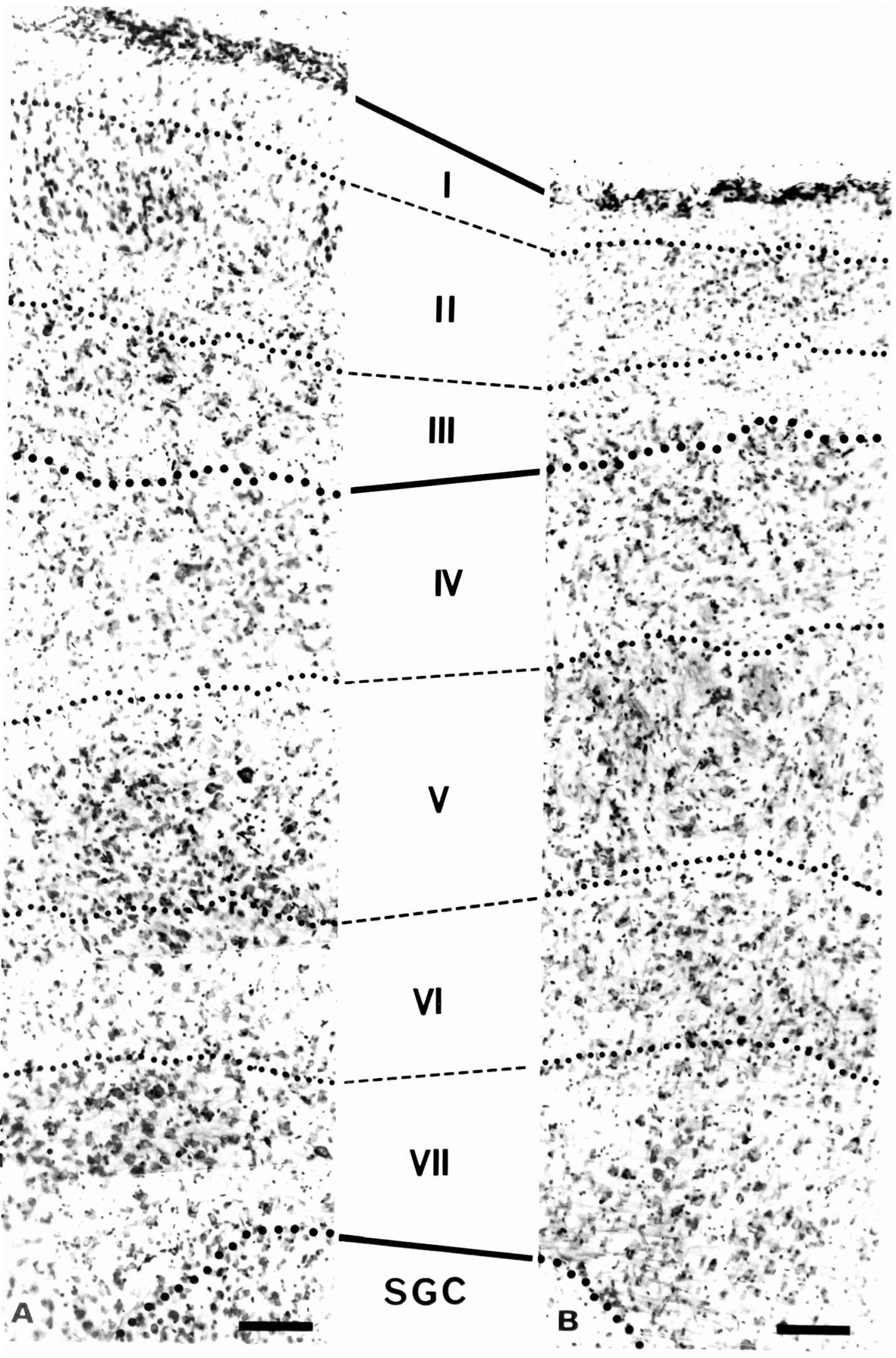




\section{Plate III}

Fig.10 A and B: Neurons of the zonal (Z) and the superficial gray layers (GS) on the ipsilateral (A) and contralateral (B) sides of a unilaterally microphthalmic rat. Many neurons in the ipsilateral superficial gray lamina (SGC) and characterized by a fusiform cell body with its long axis oriented perpendicularly to the tectal surface, as seen in the normal. However, the contralateral SGC is densely packed with small round cells and the intralaminar arrangement of the SGS neurons is highly disordered. Klüver-Barrera staining. Bar indicates $100 \mu \mathrm{m}$.

$\mathrm{C}$ and D: The parabigeminal nucleus (PB) of a normal (C) and a unilaterally microphthalmic rat (D). Three subdivisions of $\mathrm{PB}$, as shown in the normal (C), are also identifiable in the mutant rat. D: Dorsal subdivision of $\mathrm{PB}, \mathrm{M}$ : Middle subdivision of $\mathrm{PB}, \mathrm{V}$ : Ventral subdivision of PB. KlüverBarrera staining. Bar indicates $100 \mu \mathrm{m}$. 


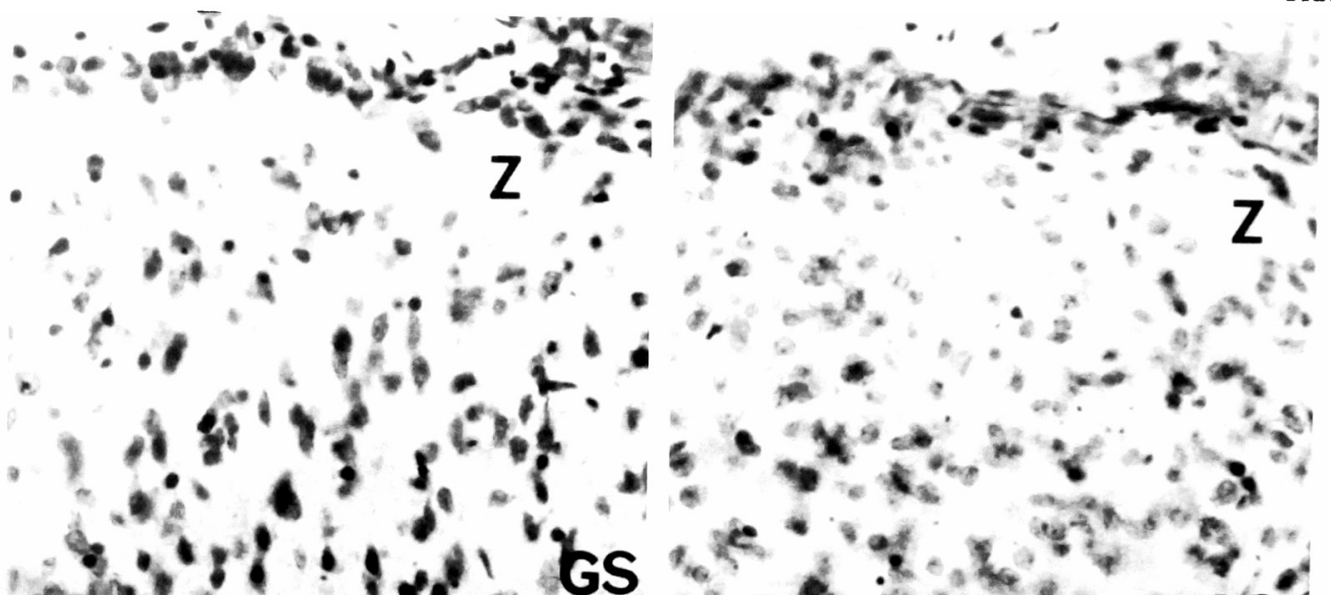

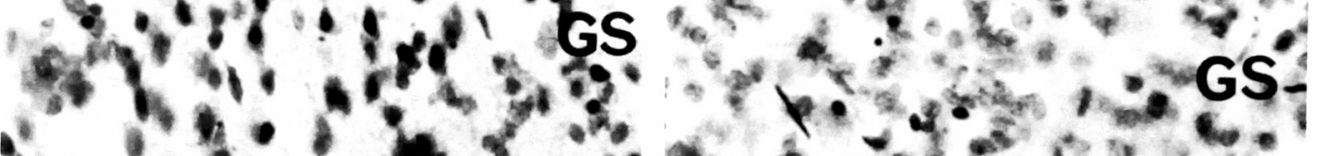
\&.

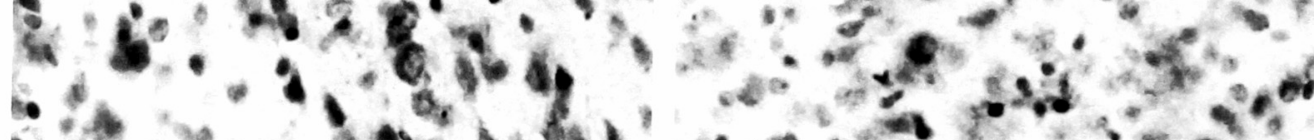

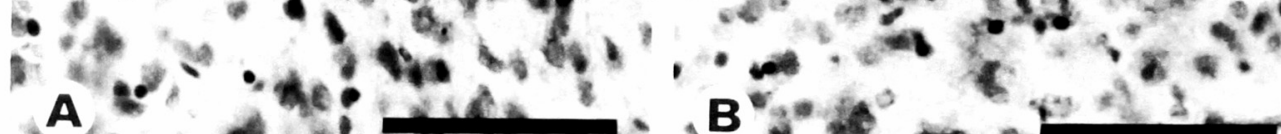

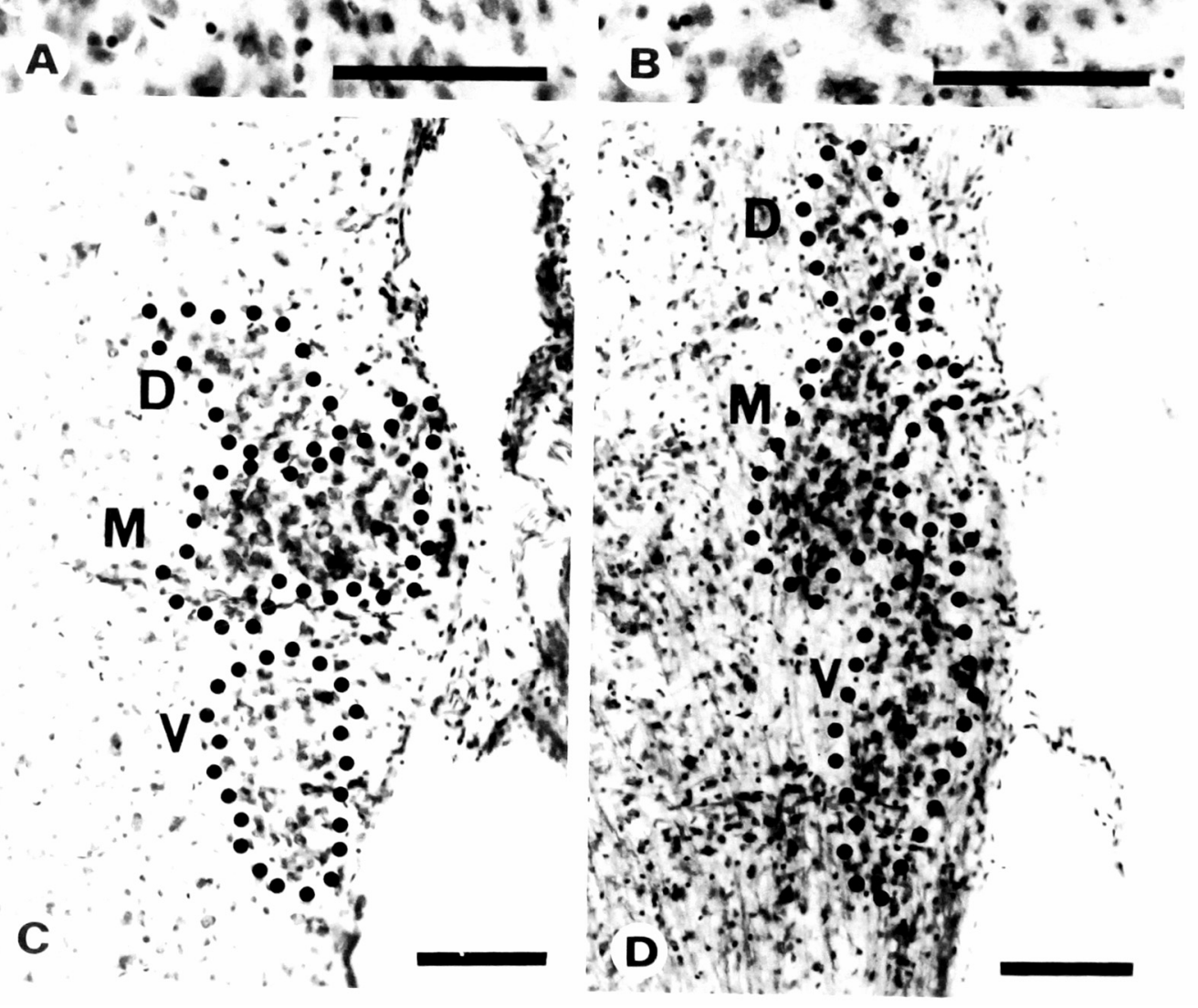

